\title{
A IMPORTÂNCIA DO ENSINO DAS ARTES VISUAIS NA EDUCAÇÃO INFANTIL
}

\author{
Robson Canteiro Valenzuela ${ }^{1}$ \\ Debora Regina Lambreht ${ }^{2}$
}

RESUMO: O presente trabalho buscou reverenciar a importância do ensino das Artes Visuais na Educação Infantil em meio escolar. Assim, obteve-se como objetivo geral refletir a importância do ensino das Artes Visuais na Educação Infantil em meio escolar. Para tanto foi necessária a elaboração de objetivos específicos que norteassem e alcançassem a finalidade principal, em que foi realizado levantamento bibliográfico durante o estudo sobre os conceitos e interpretações de autores renomados das Artes Visuais e sua contribuição em âmbito escolar. Para agregar no estudo, a pesquisa bibliográfica levantou e refletiu sobre as evoluções e influências das Artes Visuais desde as séries iniciais. Este trabalho também teve como base a pergunta problema: Qual é a importância e contribuição do ensino das Artes Visuais na Educação Infantil? A metodologia empregada foi de caráter exploratório e descritivo, pesquisa bibliográfica e análise de conteúdo. Ao final deste trabalho pode-se afirmar que todos os objetivos foram devidamente alcançados e a pergunta norteadora respondida, uma vez que as Artes Visuais proporcionam, cada vez mais, o desenvolvimento de raciocínio e social, assim como alavanca a criatividade dos alunos na execução das tarefas e associação das outras disciplinas.

Palavras-chave: Artes Visuais. Educação Infantil. Criatividade.

ABSTRACT: This paper sought to review the importance of teaching Visual Arts in early childhood education in a school environment. Thus, the general objective was to reflect on the importance of teaching Visual Arts in early childhood education in a school environment. To do so, it was necessary to elaborate specific objectives to guide and reach the main purpose, in which a bibliographic survey was carried out during the study about the concepts and interpretations of renowned authors about the Visual Arts and their contribution in the school environment. To add to the study, the bibliographic research surveyed and reflected on the evolution and influence of Visual Arts since the early grades. This work was also based on the problem question: What is the importance and contribution of teaching Visual Arts in early childhood education? The methodology used was exploratory and descriptive, bibliographic

\footnotetext{
${ }^{1}$ Possui graduação em Artes Cênicas - Licenciatura pela Universidade Federal da Grande Dourados (2016), possui pós-graduação em Artes Visuais pela Faculdade Venda. Nova do Imigrante - FAVENI (2017), cursou Segunda Licenciatura em Pedagogia na Faculdades Magsul (2018).E-mail: robinn.valenzuela@gmail.com.

${ }^{2}$ Especialista em Alfabetização e Letramento, Licenciada em Artes Cênicas/Teatro pela UFGD - Universidade Federal da Grande Dourados. Foi bolsista do PIBID -Programa Institucional de Bolsas de Iniciação à Docência no Subprojeto de Artes Cênicas da mesma universidade. Tem experiência na área de Arte, com ênfase em Teatro.. Professora de Arte na Escola Estadual Onze de Março, em Cáceres/MT.
} 
research and content analysis. At the end of this paper, it can be stated that all objectives were duly achieved and the guiding question answered, since the Visual Arts provide, increasingly, the development of reasoning and social, as well as leveraging the creativity of students in the execution of tasks and association of other disciplines.

Keywords: Visual Arts. Early Childhood Education. Creativity.

\section{INTRODUÇÃO}

A arte em si está presente no cotidiano da sociedade, porém, ao compreender o ensino das Artes Visuais em âmbito escolar é possível visualizar as diferentes culturas do Brasil. "Ao estudar sobre as culturas do povo brasileiro, busca-se que a criança amplie a noção de diversidade cultural, a forma que as sociedades se estruturam em suas diferentes formas de manifestações" (BARBOSA, I991, p. 44).

Ao experimentar o ensino-aprendizagem das Artes Visuais nas escolas pode-se entender o objetivo das atividades artísticas para o desenvolvimento da criatividade das crianças, pois "a atividade artística inclui tanto a produção de desenhos, músicas, pinturas, coreografias, mímicas, gravuras, fantoches, etc., quanto a apreciação da produção cultural” (LACERDA, 2009, p. 19).

Portanto, este estudo tem como tema central a importância do ensino-aprendizagem das 223 Artes Visuais da Educação Infantil, tendo como objetivo geral refletir a importância do ensino dessa linguagem na Educação Infantil em meio escolar formal. Para alcançar este objetivo geral foi necessário o desdobramento do mesmo em objetivos específicos: conhecer as evoluções históricas e discutir sobre a influência da arte na Educação Infantil.

$\mathrm{O}$ artigo justifica-se pelo que se referem aos sentidos, emoções e capacidade de visualizar o mundo de forma lúdica, isto é, a criança consegue utilizar a arte como ferramenta de percepção da realidade em que se encontra e a linguagem artística pode ser facilitadora na compreensão dos acontecimentos pelo mundo e a evolução do indivíduo, construindo, assim, saberes de forma coerente ao âmbito educacional presente.

Metodologicamente o trabalho utilizou-se de caráter exploratório e descritivo, pesquisa bibliográfica e análise de conteúdo. Estes elementos foram essenciais para levantar informações 
sobre as Artes Visuais, assim como a análise de conteúdo tornou-se importante para a reflexão final sobre a importância do tema na Educação Infantil.

Assim, utilizou-se de levantamento bibliográfico a fim de agregar no referencial teórico sobre as evoluções e influências das Artes Visuais desde as séries iniciais, no qual tornou-se relevante a este estudo por apresentar autores renomados com suas visões sobre o objeto de estudo.

O trabalho se estruturou a partir de uma revisão de literatura sobre os temas anteriormente mencionados em que. a partir destas visões, foi possível concluir a relevância das Artes Visuais em âmbito escolar, principalmente nas séries iniciais, isto é, na Educação Infantil. Ao final são apresentados os autores utilizados para argumentar o trabalho.

\section{REVISÃO TEÓRICA}

Neste capítulo serão expostos alguns pontos de vista de autores que discutem e refletem sobre a evolução da arte e a influência dessa área do conhecimento no meio escolar, sendo essencial para agregar conhecimento ao estudo realizado.

\subsection{A arte: evoluções históricas}

Desde o início dos tempos o homem tem a necessidade de se expressar para conseguir aquilo que tem necessidade. Na Pré-História, por exemplo, o homem que habitava a terra relatava nas paredes de suas cavernas a sua vida diariamente. Pintavam imagens de animais que eram caçados por eles e depois consumidos, imagens das suas descobertas como as ferramentas utilizadas por eles, o contato que tinham com o fogo, a sua grande descoberta, além de pintarem, também, o modo como se relacionavam na comunidade por eles criada.

Com o passar do tempo apareceram os egípcios, pessoas com inteligência mais desenvolvida em relação aos homens das cavernas. Nessa época surgiu a escrita e as crenças e exercícios da fé nos deuses. Com a escrita eles puderam se comunicar de forma clara e eficiente, podendo, inclusive, compartilhar tudo aquilo que pensavam, estabelecendo, assim, relações de ensino e aprendizagem. Sua principal contribuição para a arte foram as suas esculturas, a 
começar pelas pirâmides, que eram grandes construções que mostravam a sua riqueza e sua grandeza, governados por uma homens tidos por superiores, os faraós.

Por acreditarem em deuses e vida após a morte eles eram alocados em sarcófagos, muitos deles feitos de ouro, o que mostrava a riqueza de seu faraó. Esses sarcófagos eram um tipo de expressão artística por se tratar de uma escultura.

Outra grande fase da arte na História foi na Grécia, lugar onde foram construídos vários monumentos e estátuas feitas de mármore. Junto a isso, apareceram filósofos cujo meio de representação artística era a poesia e os textos.

Já na Roma antiga, a forma de expressão artística foram as grandes construções, com o uso de mosaicos, utilização de pedras encaixadas, formando símbolos geométricos, no lugar da pintura. Houve o surgimento de muitas igrejas, que eram construídas com a utilização de muitos recursos. Essas igrejas eram construções grandiosas e imponentes, com grandes arcos de entrada e cúpulas mostrando a religiosidade e sua adoração às suas crenças.

Nesta época surgiram outros movimentos artísticos como o Barroco, o Renascimento e o Rococó, que contribuíram para alavancar a Arte Moderna com pinturas requintadas com valorização dos sentimentos dos artistas. Houve também mudanças na construção de ambientes internos, tinham pontos de destaque na decoração dos ambientes e a colocação de ornamentos, 225 o que trazia um aspecto artístico para o interior dessas construções, além de uma maior organização.

O processo de transformação da arte traz também a era Moderna, com pinturas abstratas que tem em sua composição várias formas geométricas ou não, que trazem àquele que a observa os mais variados sentimentos, entendimentos e sensações. Junto a isso surgiram outras formas de expressão, como algumas construções imponentes, como a Torre Eiffel.

A arte a cada dia se transforma. Ela não tem um fim e a cada aparição de novas expressões artísticas é mais um ponto a se colocar em sua linha de tempo, transformando o mundo em um lugar mais atrativo com cada vez mais lugares, pinturas e esculturas a serem apreciadas e cativando e inspirando as novas gerações a desenvolver suas próprias expressões artísticas. 


\subsection{A Influência da Arte na Educação Infantil}

Neste item serão abordadas as influências da arte na Educação Infantil, tendo em vista o desenvolvimento da criança a partir das séries iniciais. Para início de argumentação é fundamental visualizar os processos que circundam a relação da arte com o processo da criança:

Fazer arte reúne processos complexos nos quais as crianças integram vários elementos de sua experiência. No processo de seleção, interpretação e transformação, mostra como você pensa, como se sente e como se parece. De acordo com seu estágio evolutivo, a criança representa as coisas que lhe interessam e as coisas que ela domina em sua criação artística. A obra de arte não é uma representação das coisas, mas uma representação da relação entre o artista e as coisas. [...] quanto mais você avança na arte, mais você entende e demonstra autoconfiança, independência, comunicação e adaptabilidade social (ALBINATI, 2009, p. 4).

Diante da visão de Albinati (2009), o envolvimento da criança com a arte se dá desde suas experiências, como por exemplo, a interpretação e a decodificação de sons, frases, imagens, isto é, intensifica a criatividade da criança no meio em que vive.

Através deste estímulo da criatividade, Sans (1995) se refere a associação de formas para representar seu raciocínio e sua releitura das práticas cotidianas:

depois que a criança desenha o sol irradiante, parece descobrir um tipo de fórmula para representar o rosto humano. Geralmente, ela desenha dois pequenos círculos representando os olhos, um ponto como se fosse o nariz e um risco horizontal como boca (SANS, 1995, p. 28).

Desta forma, a capacidade de uma criança em reinterpretar seus pensamentos e objetos ao seu redor faz com que possa traçar linhas e formas semelhantes ao original, porém com sua própria originalidade nos detalhes, como o desenho de uma casa com os móveis, de acordo com suas lembranças e conhecimentos (SANS, 1995).

Ainda para Sans (1995) a criança faz o que gosta e vivência, assim alcança com suas brincadeiras e desenhos sua satisfação. Esta forma de se satisfazer de forma harmônica é denominada como modo lúdico. No caso de não ser exercitada e experimentada, essa ludicidade, a criança perde sua inocência, se transformando em uma criança sem criatividade e gosto pelas atividades infantis, fazendo com que ela se torne, assim, um adolescente precocemente.

A criança com sua inocência transforma, através de sua visão, o mundo em que vive, sendo assim, ela consegue transmitir em seus desenhos a maneira como imagina a sociedade 
que se relaciona. Perante a isso Martins, Picosque e Guerra (1998) expõem suas ideias da seguinte forma:

Seu pensamento se dá na ação, na sensação, na percepção, sempre regado pelo sentimento. Convive, sente, reconhece e repete os símbolos do seu entorno, mas não é, ainda, um criador intencional de símbolos. Sua criação focaliza a própria ação, o exercício, a repetição (MARTINS, PICOSQUE e GUERRA, I998, p. 96).

Com base nisso, pode-se observar que a criança não possui total capacidade de criação, no entanto, é possível visualizar as práticas de desenvolvimento lógico, por meio de exercitação e reprodução de ideias.

Esta reprodução se dá pela leitura do mundo e os acontecimentos ao redor de uma criança, pois ao longo do tempo ela desenvolve sua aptidão em interpretar músicas, cantigas, teatro e ilustrações e demais expressões artísticas, porém, para tanto, é fundamental o acompanhamento de outras pessoas para guiá-la, assim:

[...] a comunicação entre as pessoas e a leitura do mundo não se dá apenas por meio de palavras. A maior parte do conhecimento sobre os pensamentos e sentimentos das mais diversas pessoas, nações, países e épocas é o conhecimento que adquirimos completamente por meio de sua música, teatro, pintura, dança e filmes (MARTINS; PICOSQUE; GUERRA, i998, p.14).

É essencial o estímulo nas crianças de práticas oratórias, visuais e gestuais para garantir que elas entendam e aprendam com isso, alcançando, assim, um bom nível de conhecimento. Dessa forma se garante que cresçam sabendo como eram os pensamentos e educação de outras pessoas em épocas diferentes.

Ao relacionar os conhecimentos de uma criança sobre o mundo de forma geral com o ensino da arte é possível vislumbrar de diferentes modos, pois;

[...] aguça a sensibilidade, pois trabalha constantemente com a emoção e os sentidos. Por meio da educação artística consegue-se levar à percepção sobre coisas do mundo e da própria natureza humana as quais, dificilmente, seriam apreendidas por um indivíduo sem tal formação. Quanto maior o contato com a linguagem da arte, com a linguagem artística, maior nossa capacidade de apreensão e de percepção da realidade vivida (NEVES, 2011, p. 40).

No que se refere aos sentidos, emoções e capacidade de visualizar o mundo de forma lúdica, a criança consegue utilizar a arte como ferramenta de percepção da realidade em que se encontra, uma vez que a linguagem artística facilita na compreensão dos acontecimentos pelo 
mundo e a evolução do indivíduo, assim construindo saberes de forma coerente ao âmbito educacional presente.

Nota-se que as atividades lúdicas como a arte se tornam uma ferramenta indispensável para o desenvolvimento infantil, a qual estas atividades servem como meio de socialização de crianças com adultos, pois, apesar de pensamentos e maturidade diferentes, a criança pode transmitir o espírito de diversão e recreação dos fatos e situações ocorrentes no cotidiano.

Portanto, a arte na Educação deve trazer consigo elementos do saber, interesse pelo novo e formas de expressão, assim;

A arte na Educação busca a intensificação do interesse por novas criações, pela reflexão e pelo desenvolvimento de uma capacidade crítica, visando à formação de sujeitos ativos e autênticos. É exatamente neste sentido que a Arte na Educação atua como veículo de transformação e um canal para o vislumbre de novas possibilidades, novos horizontes. $O$ aluno deve ser trabalhado na sua totalidade: corpo, mente e espírito. Através desse processo, ele automaticamente vê a razão sob uma nova ótica. $\mathrm{Na}$ verdade, a inserção da Arte na Educação propõe uma releitura integral e profunda do processo de aprendizagem, e não apenas de forma verborrágica. Educar com Arte significa educar através do contato com o outro, do despertar dos sentimentos e da troca. É sair de si mesmo para enxergar o outro. O que se almeja é que a descoberta interiorizada de sentimentos reais evolua para a externalização dos mesmos de maneira consciente e engajada (LACERDA, 2009, p. 133).

A criança, ao estabelecer relações entre o mundo e as pessoas, interage com o meio, 228 manifestando suas emoções, suas conquistas, que podem modificar o ambiente. Como o meio físico é fator determinante para estimular e motivar as aprendizagens, é imprescindível que o professor esteja atento ao organizá-lo para que as crianças possam brincar e interagir de forma criativa e desafiadora.

A arte promove o desenvolvimento de competências, aptidões e conhecimentos exigidos nas diferentes áreas de estudo; no entanto, isso não é motivo para incluí-la nos currículos escolares, mas sim o seu valor intrínseco como arquitetura humana, como um património comum que pode ser utilizado por todos (IAVELBERG, 2003, p.9).

O pensamento da criança se adapta conforme o ambiente em que está, e uma vez que são incorporados conhecimentos primordiais para a criança e ainda unindo com diversão e alegria, é possível ter maior interação da criança com o conteúdo praticado. Sendo assim, mostra-se necessário o ensino da arte nas escolas. Para Ana Mae Barbosa (I99I)

A arte não é apenas a base, mas também a base da educação nos países em desenvolvimento. Arte não é decoração. Arte é cognição, profissão e outra forma de 
interpretar o mundo. Realidade é imaginação e conteúdo. Como conteúdo, a arte representa o melhor trabalho da humanidade (BARBOSA, 1991, p.4).

A arte não deve ser encarada apenas como um simples desenho a ser exposto e apreciado por pessoas, mas sim como uma forma de manifestação dos sentimentos do autor da obra, seja ele um artista renomado ou uma criança das séries iniciais. Por isso se deve um valor maior a essa disciplina nas escolas, pois mostra aquilo que queremos expressar sem precisar necessariamente fazer o uso da fala.

Para uma melhor aprendizagem por parte das crianças dentro das escolas deve-se incentivá-las e acreditar em seu potencial para fazer aquilo que elas imaginam. Dessa forma, a criança desenvolve melhor o seu intelecto, podendo, assim, desenvolver seu lado artístico e expor suas ideias. Portanto é fundamental dar a elas esse espaço de criação, pois ele auxilia em seu processo de aprendizagem, proporcionando uma experiência produtiva e prazerosa dentro de sala de aula.

\section{CONCLUSÃO}

A presente pesquisa conferiu uma refletir acerca da importância do ensino das Artes Visuais no ambiente escolar - Educação Infantil - a partir de questões norteadoras, como: "qual 229

a importância e contribuição do ensino das Artes Visuais na Educação Infantil?”, visando responder a essa questão e atingir o objetivo principal, observando e mencionando a contribuição das Artes Visuais para os alunos da Educação Infantil a partir de alguns autores.

Por conseguinte, torna-se claro que o processo de ensino e aprendizagem de Artes Visuais proporciona aos alunos uma variedade de habilidades, com o objetivo de exercitar a coordenação motora por meio do desenho e do recorte de papel, por exemplo. Pode-se considerar também que as Artes Visuais são a base da formação do aluno para se expressarem e se compreenderem.

Com isso, ao longo do estudo, evidenciou-se a importância do ensino das Artes Visuais na Educação Infantil, em que a educação através da arte contribui para o desenvolvimento da criatividade, autonomia e espontaneidade. Portanto, o conhecimento adquirido pelos alunos com base na arte os torna mais críticos e reflexivos. 
Ainda, destaca-se que objetivo do ensino de Artes Visuais é proporcionar desenvolvimento para a vida das crianças e deve ser visto como uma forma de construir conhecimento, compreender o mundo e expressar emoções. Deste modo, as Arte Visuais na Educação Infantil estão relacionadas à sua vivência, expressando, ampliando o conhecimento, desenvolvendo a criatividade e o pensamento estético.

Tendo em vista a contribuição das Artes Visuais na Educação Infantil, destaca-se a importância desse tipo de ensino, pois, ao vivenciar a arte desde as séries iniciais, as crianças aprendem a valorizar a cultura social. Por isso é necessário reexaminar o ensino das Artes Visuais nas escolas, uma vez que para uma aprendizagem significativa é fundamental o comprometimento dos educadores, como planos de atividades, definição de metas a serem alcançadas e utilização de materiais diversos.

\section{REFERÊNCIAS BIBLIOGRÁFICAS}

ALBINATTI, Maria Eugênia Castelo Branco. Artes visuais. Artes II. Belo Horizonte. 2009.

BARBOSA, A.M.T.B. A imagem no ensino da arte: anos oitenta e novos tempos. São Paulo: Perspectiva; Porto Alegre: Fundação IOCHPE, I99I.

IAVELBERG, R. Para gostar de aprender arte: sala de formação de professores. Porto Alegre: Artmed, 2003.

LACERDA, Vivian. A importância da arte na educação - vida plena à cidadania. 2009. Disponível em: http://www.rumosdobrasil.org.br/2009/ro/29/aimportancia-da-arte-daeducacao-vida-plena-a-cidadania/. Acesso em 3i de outubro de 2017

MARTINS, Mirian C.; PICOSQUE, Gisa; GUERRA, M. Terezinha Telles. Didática do ensino de arte: a língua do mundo: poetizar, fruir e conhecer arte. São Paulo: FTD, I998.

NEVES, Renato de Souza. A estética de Lukács. Um olhar sobre o homem e o mundo por meio da obra de arte. 2011.

SANS, Paulo de Tarso Cheida. A criança e o artista: Fundamentos para o ensino das artes plásticas. 2. ed. Campinas, SP: Papirus, 1995. 